\title{
Using nanofiller assemblies to control crystallization kinetics of high-density polyethylene
}

Kamlesh Bornani, ${ }^{\dagger}$ Md Anisur Rahman, ${ }^{\S}$ Brian Benicewicz, ${ }^{\S}$ Sanat K. Kumar ${ }^{t} *$ and Linda

\author{
Schadler ${ }^{\dagger} *$ \\ ${ }^{\dagger}$ Department of Department of Mechanical Engineering, College of Engineering and Mathematical Sciences, University \\ of Vermont, Burlington, Vermont 05405, United States. \\ ¥Department of Chemical Engineering, Columbia University, New York, New York 10027, United States.

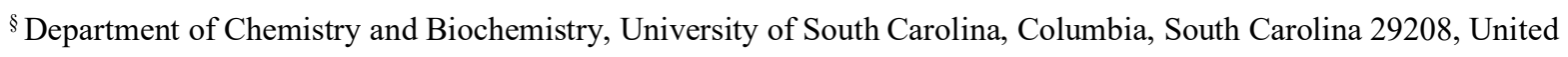 \\ States.
}

KEYWORDS polyethylene nanocomposites; polymer-grafted nanoparticles; polymer crystallization; nucleation and crystal growth. 


\section{Supporting Information}
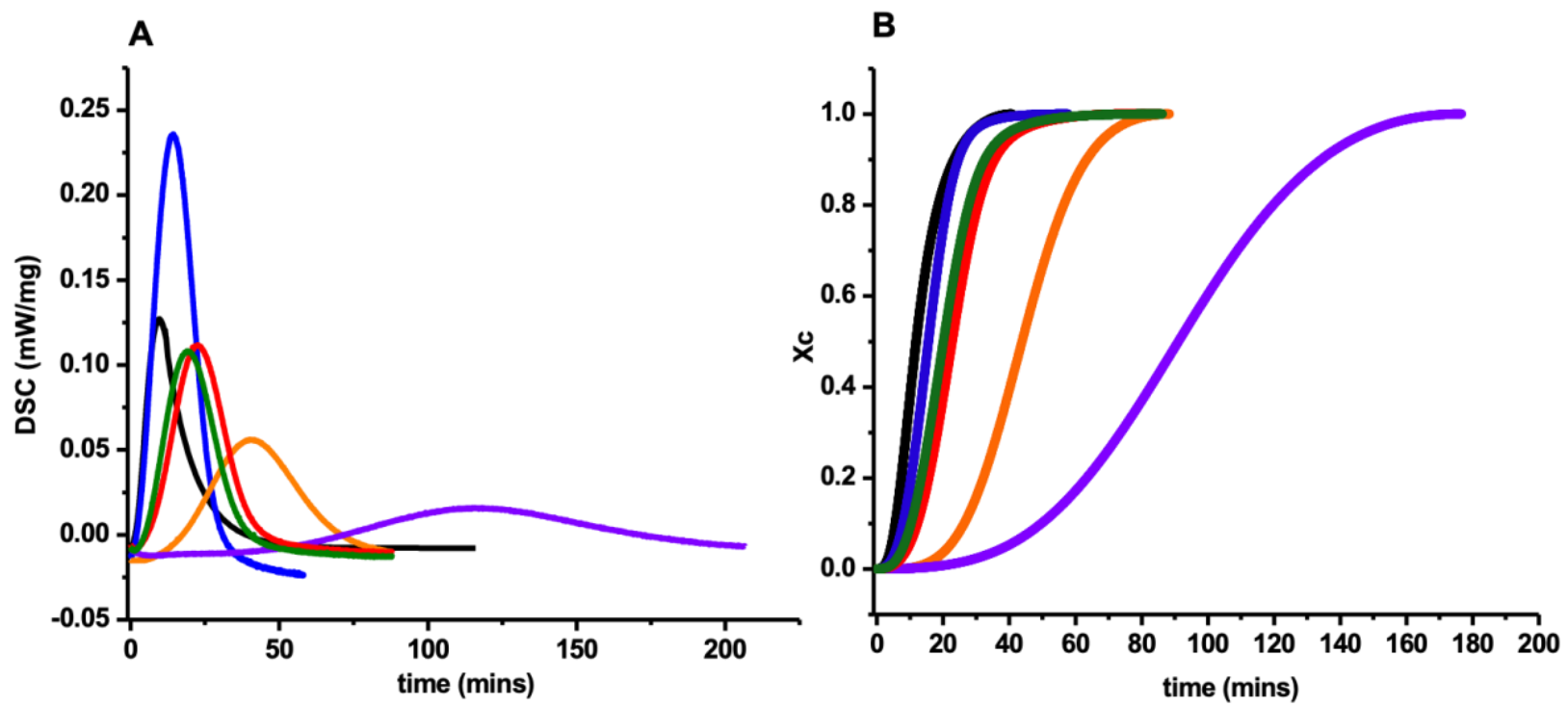

Figure S1. Overlay of heat of fusion curves (A) and plots of crystallinity vs time (B) showing bulk

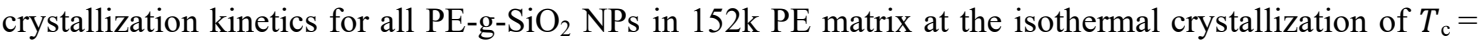
$124^{\circ} \mathrm{C}$.

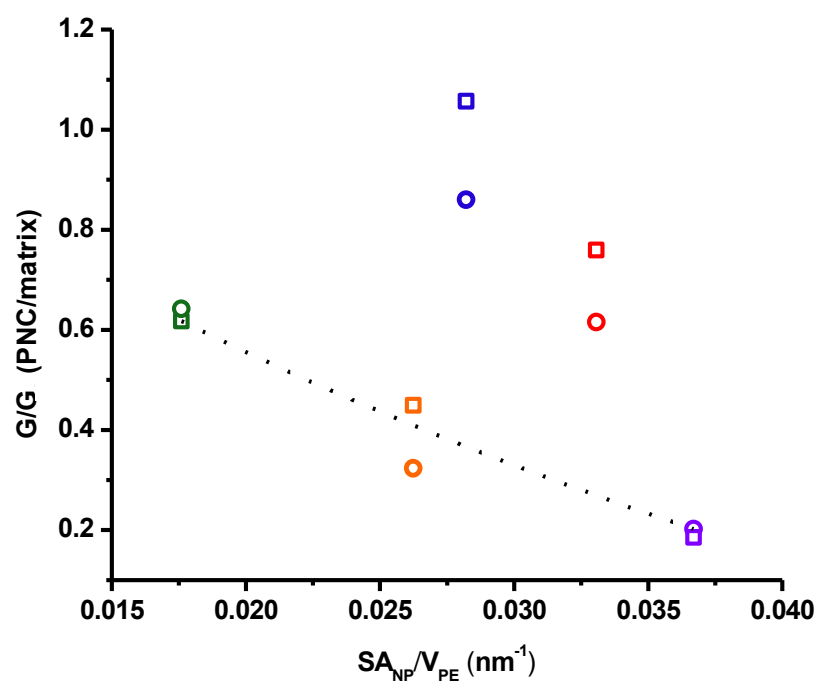

Figure S2. Shows the confinement effect by plotting average normalized growth rates $G / G$ (PNC/Matric) from both POM (square) and DSC (circle) without the overlay plot, as a function of $S A_{\mathrm{NP}} / V_{\mathrm{PE}}$. 